\title{
Happiness breeds prosperity
}

\author{
The Politics of Happiness: What \\ Government Can Learn from the New \\ Research on Well-Being \\ by Derek Bok \\ Princeton University Press: 2010. 272 pp. \\ $\$ 24.95, £ 16.95$
}

It has long been assumed that economic prosperity brings happiness. However, the evidence is to the contrary. Economic growth in developed countries has gone hand-inhand with a rise in mental and behavioural disorders, family breakdown, social exclusion and diminished social trust. In China, for example, a 2009 study by German sociologists showed that the lifting of hundreds of millions of people out of poverty in the 1990s has been accompanied by an alarming decrease in life satisfaction at every level of income, in both rural and urban areas.

In The Politics of Happiness, law professor Derek Bok, a former Harvard president, argues that it is time to rethink the goal of politics: to promote well-being rather than wealth. His appeal that this is both necessary and timely rests on two key points: first, that there is an increasingly solid body of evidence about the causes of happiness and its individual, social and environmental benefits; and second, that most people are unaware of and need education about what will give them lasting satisfaction.

Bok reviews a wide range of surveys that consistently associate levels of happiness or satisfaction with several demographic and social variables. These include close relationships, marriage, employment, religious or spiritual practices, social trust and good governance, as well as having non-materialistic values, civic engagement and helping others. Although such associations do not necessarily imply causation - married people are generally happier than unmarried people, for example, but happier people are more likely to get married - longitudinal data are more compelling. For instance, a style of parenting that fosters the later mental health and well-being of adult children combines warmth and interest in the child with firm guidance that is authoritative but not authoritarian. Longitudinal research has also recently established that a father's parenting style can have a greater impact on future well-being than a mother's.

The most persuasive evidence about the causes and consequences of happiness comes from experimental research, although this receives scant attention in Bok's book. For example, in a 2008 study, participants who were given a sum of money and told to spend it on someone else showed higher happiness scores than those who were instructed to spend it on themselves. Other experimental studies demonstrate that positive emotions or attitudes produce a range of benefits: broader focus of attention, more creative think-

ing, tolerance or kindness to others, a reduced physiological response to stress and improved immune function. We can conclude that happiness has social causes and produces both social and individual benefits.

Happiness is a legitimate goal for government policy, Bok argues, because it is more than a private, transient feeling. Lasting happiness - well-being or 'flourishing' - depends on the ongoing process of how we live our lives. Well-being encompasses close relationships, utilizing our strengths, helping others, having a sense of purpose and believing that what we do makes a difference. Hence the pursuit of lasting happiness can lead to the development of more productive, cohesive, caring and sustainable societies.
Bok's second contention is based on studies revealing that people do not understand what will make them happy, and thus fail to act accordingly. The solution, he asserts, requires a political response through mass education. Wealth, possessions, appearance or fame do not bring lasting happiness, despite the messages promulgated by advertisers and the media. Bok proposes transformative education such as coaching parents, instructing teachers and providing school children with the knowledge of how to lead satisfying lives. Quality programmes that improve social and emotional skills in school children, or broader projects such as the Harlem Children's Zone in New York - which supports families through parenting workshops, pre- and after-school programmes and child-oriented health schemes - have demonstrably improved personal development, relationships and academic achievement. Happiness is a skill that can be learned.

Bok concludes that the scientific evidence on well-being is now robust enough for politicians to start taking action. Writing from a US perspective, he proposes the provision of universal health insurance and measures to strengthen marriages, such as premarital education and incentives to persuade lowincome couples to marry. The United Kingdom is ahead in translating the evidence into interventions.

For example, policies recommended in the Foresight Project Report on Mental Capital and Wellbeing (see Nature 455, 1057-1060; 2008) are being implemented through wellbeing audits across government departments that are responsible for schools, work, communities and health. An All-Party Parliamentary Group on well-being economics has also been set up to challenge the government's use of

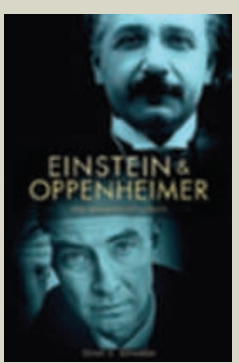

Einstein and Oppenheimer: The Meaning of Genius

by Silvan S. Schweber (Harvard Univ. Press, \$18.95) Looking at Albert Einstein and J. Robert Oppenheimer in their social contexts, Silvan Schweber expands our understanding of these iconic physicists and how they used the local resources available to them. He questions what is meant by genius and whether, by putting some scientists on pedestals, we overlook the achievements of the communities they came from.

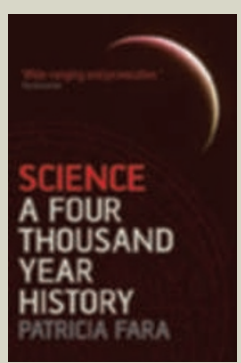

Science: A Four Thousand Year History by Patricia Fara (Oxford Univ. Press, $£ 9.99$ ) In her global view of science history, Patricia Fara moves away from the common, Eurocentric view that science began in the seventeenth century. Taking us on a journey through Babylon, China and beyond, she reveals that science has always belonged to the practical world - rather than the theoretical arena - and that its application is a result of the culture from which it sprang. 
gross domestic product as its main indicator of national success, and to promote new measures of social progress.

Three concepts are fundamental to the success of such policies. First, the creation of well-being requires more than the remediation of problems - this merely reduces ill-being. It requires that the whole population is shifted towards flourishing. Second, sustainable happiness results from what we do, not what we have; we need to be able to create our own well-being and contribute to that of others. Third, we cannot assume that translating the evidence into interventions will produce a flourishing society; we must commit to rigorous evaluation to find out what works, for whom, for how long, for which outcomes and in what contexts.

Rigorous evaluation must include analysis of long-term economic benefits. "Happiness and social
well-being are likely
to bring economic
prosperity." Preliminary analysis of the economic benefits of shifting a population - such as children with behavioural problems - towards flourishing suggests that relatively low-cost interventions may produce substantial long-term savings by reducing the need for crisis management, imprisonment or the treatment of disorders. Developments in the measurement of well-being, such as the
National Accounts of Well-being initiated by the London-based New Economics Foundation, will have a central role.

We may have been wrong to believe that economic prosperity would bring happiness, but the evidence suggests that happiness and social well-being are likely to bring economic prosperity. Moreover, where prosperity arises from postmaterialist values, it has the potential to enhance well-being without costing the earth.

Felicia Huppert is a professor of psychology in the Department of Psychiatry and director of the Well-being Institute at the University of Cambridge, Cambridge CB2 2QQ, UK. She is co-author of The Science of Well-Being with Nick Baylis and Barry Keverne.

e-mail: fah2@cam.ac.uk

\section{Signatures of life on other worlds}

\section{How to Find a Habitable Planet \\ by James Kasting \\ Princeton University Press: 2010. 360 pp. $\$ 29.95, £ 20.95$}

In the 15 years since the discovery of the first planet around a star other than our Sun, we have found more than 400 such exoplanets but there is still no place like home. In How to Find a Habitable Planet, James Kasting extends knowledge of the planets in our Solar System to searches for distant Earth-like exoplanets that could harbour life.

Kasting is a visionary best known for his computer models that established the concept of 'habitable zones' around stars - regions where planets could host conditions conducive to life, such as liquid water. His research is wide ranging, from modelling ancient runaway glaciations on a 'Snowball Earth' to examining a distant future in which our planet might, like Venus, forever lose its precious oceans. The likelihood of discovering Earthlike planets around other stars in the next few years motivates Kasting to hunt for chemical signatures of life that might be detected in their atmospheres.

The search for extraterrestrial life is often equated with one project, the Search for Extra-Terrestrial Intelligence, or SETI. Its goal of detecting radio transmission from advanced technological civilizations is laudable - the cost is low and even a null result has an enormous pay-off in terms of understanding our place in the Universe. Whether the signal comes from potential predators, friends or the distant, unreachable echoes of other life forms, this is a story that humanity yearns to hear. However, it is a good bet that most life in the Universe will be simpler than us and mimic that on Earth, where single-celled organisms constitute the bulk of the biomass.

Discussing Earth's history, Kasting explains how prokaryotic cyanobacteria transformed the early anaerobic atmosphere on Earth into an oxygen-rich environment. These simple organisms paved the way for more complex species, but they also imprinted on our

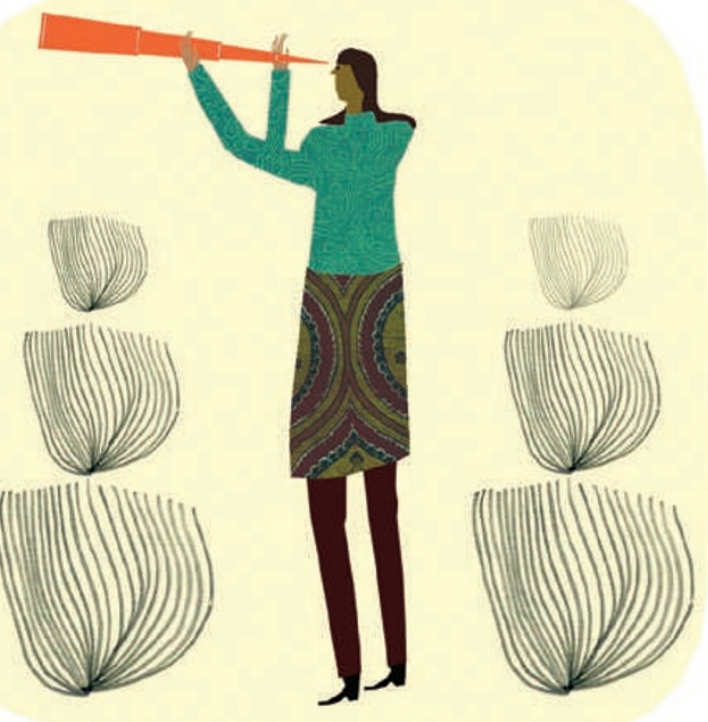

atmosphere a chemical signature of a living world: oxygen. Observations of exoplanet atmospheres will cast a wide net in the search for varied forms of life.

Another clue would be pooled water on

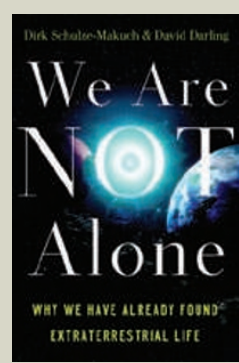

We Are Not Alone: Why We Have Already Found

\section{Extraterrestrial Life}

by Dirk Schulze-Makuch and David Darling

(Oneworld Publications, E12.99)

This provocative book asserts that extraterrestrial life exists - and that there is evidence to prove it. Describing how even the most hostile environments on Earth can support life, the authors look at how it might have evolved outside the Galaxy or on other planets and moons, including Mars, Venus, Europa and Titan.

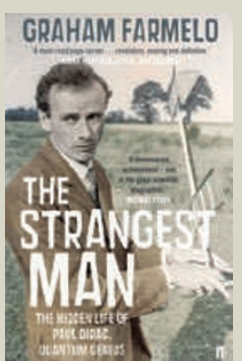

The Strangest Man: The Hidden Life of Paul Dirac, Quantum Genius

by Graham Farmelo (Faber \& Faber, £9.99) This highly praised biography sheds light on the life of physicist Paul Dirac, who is little known by the public despite his high regard among scientists. "The effortless writing style shows that it is possible to describe profound ideas without compromising scientific integrity," wrote Frank Close (Nature 462, 988; 2009). 